\title{
ÁREA: CONCEITO E PRÁXIS
}

\author{
AREA: A NEW INTERDISCIPLINARY CONCEPT
}

Dalmo de Souza Amorim

Docente. Aposentado. Departamento de Clínica Médica da Faculdade de Medicina de Ribeirão Preto - USP

CorResPondÊNCIA: Rua Bernardino de Campos, 1236 apto. 132. CEP 14.015-130 Ribeirão preto - SP. Fone fax (16)3 6364992 e-mail: dalmosamorim@uol.com.br

Este texto ocupa-se do conceito e prática da Área e dá seqüência a dois artigos ${ }^{\mathbf{1 , 2}}$ já publicados nesta revista.

Partimos de um exercício teórico que aceita um modelo. Da mesma forma que outros modelos, ele é a interpretação de uma realidade. A este designamos Área, cujos atributos aparecem abaixo. Sendo ela-a Área - a interpretação de uma realidade, temos implícito tratar-se de ente virtual, "criação", sem organização piramidal, com função definida.

A expressão - Área -, no contexto do que aqui se discute, diz respeito à integração de cursos e suas disciplinas, com um corpo de conhecimento, antecedentes próprios de educação, treinamento, métodos e conteúdos. O fundamental é a admissão de que ela é a via que promove a interdisciplinaridade.

É preciso estar atento ao fato de que ela - Área - é um "ente" imerso no meio ambiente, portanto, sujeito à influência de diversos fatores que nele existem e que podem modificá-lo. Procedem, então, três indagações.

- Primeira. "De onde ela procede"? "Procede do nada"? A resposta é: sim e não. Sob o aspecto temporal é afirmativa. Sim, não há como negar o acaso de outras iniciativas, assemelhadas, que se encontram e (eventualmente) são acolhidas. Já, sob o aspecto particular, a resposta é negativa. Não, porque ela (como aqui concebida) é mais completa e complexa que outras convencionais.

- Segunda. "Para onde ela vai"? Em meu saber, mudanças de ideologias podem transformá-la em "coisa difusa", descaracterizada, o elemento práxis preponderante sobre o ideário que lhe deu origem. À vista de ser "nova" estará sujeita a fatores de divergência e oposição; muitos deles, de extração mais conservadora, poderão concorrer para a "descontrução", da Área.

- Terceira. "Qual o critério para se aceitar a interpretação de uma realidade: a de um novo modelo"?

É minha visão que a "construção" da Área é mais do que a juntada de recursos de toda ordem: e.g.: sede física, recursos materiais, pessoal qualificado e atos normativos. Eles podem existir, sim - e existem - sem que se considere que eles representem a essência do que se pretende alcançar. O fundamental é a operacionalização da interdisciplinaridade. Ela - a interdisciplinaridade - além do conhecimento cognitivo, pode não estar acompanhada de vontade (cooperação, diálogo, abertura do conhecimento para o outro e a realização de trabalho comum).

A seguir, de modo resumido, farei referência a situações por mim vivenciadas relativas ao assunto: elas mostram que a Área pode ser operacionalizada, mais além do que teorizada. Essas experiências, todas elas, revelam que há forças inerciais, fortes e suficientes, para tentar obstaculizar a "construção" e mesmo promover a "desconstrução" da Área.

\section{ENSINO SUPERIOR}

Modelo teórico, explicativo da organização das relações (internas e externas), nas universidades, foi aqui publicado ${ }^{1}$. Porque há um modelo universal para 
instituições dessa natureza, podemos abordar o assunto de maneira genérica. Admitimos, no entanto, a diferença entre elas, por peculiaridades locais de outra natureza. Isso porque os principais domínios (prática acadêmica, cultura e estratégias) dessas instituições estão identificados pela ênfase nas atividades-fim (ensino, pesquisa e ação direta sobre o meio externo).

Tomemos o ensino como exemplo.

A organização acadêmica em departamentos, em substituição às antigas cátedras independentes, facilitou a coordenação administrativa e criou mecanismos mais justos de progressão acadêmica. Mas, ao longo do tempo, a consolidação do departamento:

- gerou atitudes conservadoras, propiciando o domínio pessoal no âmbito das especialidades, com atitudes e estilos cognitivos, representando uma subcategoria;

- a composição em especialidades e subespecialidades, culminou na formação de uma estrutura rígida, óbice à interdisciplinaridade.

Para fim de ilustração: campus de universidade pública, como o nosso, em Ribeirão Preto, é locus natural, para exercício interdisciplinar e multiprofissional. O campus dispõe de: cursos, todos de indisputável qualidade, recursos de toda ordem, pessoal docente e técnico de elevada qualidade e titulação, regime de trabalho exigido adequado para o pleno exercício das atividades-fim. Claro está que a ilustração aplica-se alhures, em mesmas condições. Mas não se operacionaliza a interdisciplinaridade.

Sem nos ocuparmos em detalhes, podemos especular, se a explicação se encontra em algumas razões isoladas ou combinadas, tais como:

- a universidade, em si mesma, é instituição relativamente jovem em nosso País;

- as escolas profissionais, isoladas, dominam a nossa história no ensino superior;

- a organização acadêmica, em geral, é em departamentos;

- as categorias profissionais são forças ativas e poderosas na construção de currículos não-ideológicos, neles identificando-se as "impressões digitais" das corporações de ofício;

- a fragmentação do conhecimento em disciplinas;

- ainda não encontramos equilíbrio no poder: ora ele é difuso, ora excessivamente centralizado;

- o aluno não ingressa na universidade, mas sim no curso.

\section{DFCVR}

O Departamento de Fisiologia Cardiovascular (DFCV), da Sociedade Brasileira de Cardiologia, está dentro dos princípios que norteiam a presente discussão: ele é "criatura", derivada de vontade coletiva, teleológica, com função presumida e sem organização piramidal. O caráter darwiniano revela-se quando, anos após a sua fundação, ele incorpora o $\mathbf{R}$ (de Respiratória). Então, ele passa para DFCVR.

Os "criadores", reconhecendo como indesejável a separação de conhecimentos básicos e de aplicação, promoveram, em agosto de 1966, reunião, na Faculdade de Medicina de Ribeirão Preto, congregando trinta e dois pesquisadores de treze instituições de ensino e pesquisa.

Provavelmente, valia mais o exemplo associativo interdisciplinar - anatomistas, biofísicos, cardiologistas (clínicos e experimentadores), cirurgiões, farmacologistas, fisiologistas, patologistas, pneumologistas - e quem mais quisesse - do que as subáreas em si. A ajuda material proporcionada pelo Conselho Nacional de Pesquisa (Proc. 1819/66) e pela Fundação de Amparo à Pesquisa do Estado de São Paulo (Proc. 66/350), a essa e às reuniões subseqüentes, significava o reconhecimento da importância que a associação de cientistas básicos e de aplicação representava para o cenário científico nacional.

Desde o início, tínhamos consciência da fragilidade natural representada pela ausência de tradição da associação de pessoas das áreas básicas e clínicas para a apresentação e discussão de suas pesquisas. Mas, ela mais do que um foro para apresentação de trabalhos científicos, era uma oportunidade para a aproximação e troca de linguagem - interdisciplinar com benefício recíproco.

É claro que o DFCVR, per se, não poderia superar a dicotomia tradicional da pesquisa (na área médica, biológica e da saúde). Mas, durante duas décadas, ele promoveu, de maneira exitosa, a aproximação desses cientistas. Dezenove deles, inclusive, editaram o livro "Fisiologia Cardiovascular", de referência nacional. A superação das incongruências de nossa organização acadêmica não poderia depender, no entanto, de ações setoriais. E, para isso, não estávamos e não estamos ainda culturalmente preparados. Ao fim de duas décadas, o DFCVR sofreu processo de "desconstrução". 


\section{PÓS-GRADUAÇÃO}

Se se pode admitir que aproveita ao que aqui se discute, por analogia, recorro ao sistema de ensino superior de maior complexidade: a pós-graduação stricto sensu. É meu entendimento que a essência do novo sistema educacional é a Área ${ }^{2}$.

Para mim foi sempre claro que o legislador ao expedir o Parecer $n^{\circ} 77 / 69$ - rejeita o entendimento de que os estudos não se limitem a um "ambiente fechado": não, no departamento (com seus regulamentos, estilos cognitivos, fracionamentos, etc), mas sim em um ambiente interdisciplinar. O pressuposto básico é aquele que não estamos lidando com "coleção de conhecimentos" (disciplinas), representativos de categorias profissionais (especialidades), mas sim nos ocupando com uma "unidade acadêmica": a Área de Concentração dos estudos, em sua virtualidade.

No que pertine ao tópico, pós-graduação stricto sensu, entende-se, por Área, o campo específico de conhecimento que constituirá o objeto dos estudos escolhidos pelo candidato; e, por domínio conexo, qualquer matéria não pertencente àquele campo, mas considerada necessária para completar sua formação. Cumpre reconhecer que o mérito do sistema inclui o fato de que a pós-graduação stricto sensu não se limita apenas ao preparo de uma tese doutoral ou dissertação de mestrado. Ele compreende os estudos a que está obrigado o aluno, cobrindo ampla extensão área - do campo de conhecimento escolhido.

Já discuti ${ }^{2}$ as virtudes e as dificuldades então experimentadas quando da implantação do sistema de pós-graduação stricto sensu na Clínica Médica: a maior dificuldade era a compreensão, aceitação e funcionamento como Área, um "ente abstrato". A transposição de Departamento para Área era mais do que um exercício semântico: era preciso converter uma realidade (o Departamento, com suas múltiplas disciplinas, não integradas) em uma abstração (a Área), uma organização do espírito, com uma composição de conteúdos curriculares distinta daquele até então praticado.

\section{ÁREA DA SAÚDE}

Acabamos de perpassar as dificuldades na gênese de programas interdisciplinares nas instituições de ensino superior. Elas são, em parte, explicativas dos óbices à organização nelas de Área da Saúde. Do assunto ocupa-se esta parte. A expressão - Área da Saúde - diz respeito à integração interdisciplinar e multiprofissional de cursos (e suas disciplinas) na saúde. A ela atribui-se a função de criar uma "unidade acadêmica" com vistas a promover um novo modelo de ensino/assistência: a Área é a matriz virtual do modelo.

À concepção não passa despercebida a dificuldade de harmonizar categorias profissionais: nelas, novas proposições mexem com enraizados interesses corporativos. Antecipadamente, sabemos que nada obstante ressaltada em seus projetos pedagógicos de cursos, - a interdisciplinaridade - é de difícil promoção no âmbito de cada curso (isolado). Que dirá entre eles!

Teoricamente, a Área é promotora da interdisciplinaridade. Mas, cabe indagar.

- Por quê aquele modelo pedagógico é (ou não) acolhido em instituições de ensino superior? • Por quê a ele não são receptivas as instituições públicas? - Por quê, eventualmente, por aquele modelo se interessam (algumas) instituição de organização privada? - Por quê, em sentido prospectivo, mesmo nessas últimas pode sofrer descontinuidades após ser implantado?

As respostas, em parte, são conhecidas; outras, não. Muitas somente serão entendidas com o desenrolar do tempo. Exemplo: naquela universidade - Universidade de Uberaba, privada - que decidiu pelo acolhimento ao projeto pedagógico retrocitado.

Destaco: $\bullet$ o poder decisório é centralizador, não difuso; • os cursos viviam em "federação"; • organização não-departamental; • fragmentação do conhecimento, em disciplinas; $\bullet$ estrutura matricial, criando relações horizontais entre suas atividades-fim; • unidades operacionais de saúde isoladas, em níveis de complexidade e sob diferente gestão.

São treze os cursos na saúde: • biomedicina; • educação física; • enfermagem; • farmácia; • fisioterapia; $\bullet$ fonoaudiologia; $\bullet$ medicina; $\bullet$ medicina veterinária; • nutrição; $\bullet$ odontologia; • psicologia; • serviço social; $\bullet$ terapia ocupacional.

Todos esses cursos, em suas diretrizes curriculares, ressaltam o significado da interdisciplinaridade e a adoção da pedagogia do perfil. A partir da concepção - inclusive operacional - as partes - os cursos e recursos - foram reunidas e organizadas, de modo articulado, coordenado e hierarquizado. Dessa forma, obedecidas as características de complexidade, foi instituído um Sistema de Saúde - matriz operacional, articulado com as atividades do SUS. 
Criadas as ações tidas como estratégicas, precipitou-se o exercício prático do modelo teórico. A hipótese era a de que, após os cuidados e esclarecimentos preliminares, estando presentes e juntos os cursos (professores, alunos e meios) eles desenvolveriam atividades interdisciplinares.

A hipótese não se revelou verdadeira.

Passou-se, então, ainda sob a mesma fundamentação teórica, à criação de programa tido como aglutinador. Ele foi designado, com título autoexplicativo, Programa de Promoção de Saúde, no âmbito de conceito de Área. O Programa é a matriz instrumental: ele rompe com o convencional de ensino e práticas isoladas, permitindo ao aluno vivências antecipadas do papel profissional, trocando experiências e conhecendo especificidades dos outros cursos.
Recapitulando. A Área é a matriz virtual; o Sistema, o operacional e o Programa, a matriz instrumental. O sucesso até aqui obtido, no entanto, não traz consigo a permanência do modelo discutido. A análise prospectiva, acima destacada, considera até mesmo a descontinuidade desse projeto pedagógico em andamento.

\section{REFERÊNCIAS}

1 - Amorim DS. Linkage between higher education institutions and the community. Medicina (Ribeirão Preto) 1996; 29: 50110.

2 - Amorim DS. Memória histórica da Pós-Graduação. Medicina (Ribeirão Preto) 2005; 38: 164-7. 